\title{
ONE-POT SELECTIVE DEUTERIATION OF 5'-DIMETHOXYTRITYLATED DEOXYNUCLEOTIDE DERIVATIVES.
}

\author{
Shui-Tein Chen', Shiah-Yun Chen', Shan-Ho Chou ${ }^{2}$, \\ Chiou-Rong Chen ${ }^{3}$, Wen-Chang Huang ${ }^{3}$, Kung-Tsung Wang ${ }^{1,4 *}$.
}

1. Institute of Biological Chemistry, Academia Sinica, Taiwan.

P. O. Box 23-106, Taipei, Taiwan. 10098.

2. Howard Hughes Medical Institute, SL-15, University of Washington, Seattle, WA 98195, USA.

3. Department of Chemistry, National Taiwan Normal University.

4. Department of Chemistry, National Taiwan University.

\section{Summary}

Procedures have been developed for selective incorporation of deuterium at C-6 of 5'-DMT-dC(Bz) ${ }^{\oplus}, \mathrm{C}-8$ of 5'-DMT-dA(Bz), C-8 of 5'-DMT-dG(i-Bu), and C-6 of 5'-DMT-dT in dimethylsulfoxide solution catalyzed by various amounts of base at $90-135^{\circ} \mathrm{C}$ with quantitative or nearly quantitative deuterium-labeling yields. The reactions of deuterium exchange of C-6 of 5'-DMT-dC(Bz), C-8 of 5'-DMT-dA(Bz), and C-8 of 5'-DMT-dG(i-Bu) were performed in a one-pot reaction procedure and that of C-6 of $5^{\prime}$-DMT-dT was achieved by deuteriation of $5^{\prime}$-unprotected dT, followed by dimethoxytritylation of 5'-OH with 4,4'-dimethoxytrityl chloride.

Nucleic acid structures can be determined in solid state by X-ray crystallography'. However due to the fact that the crystal packing force ${ }^{2,3}$ or the dehydrating organic solvents used to induce crystal formation ${ }^{4.7}$ can seriously distort the solid state nucleic acid structure determined by $\mathrm{X}$-ray crystallography, it is necessary to have an alternative method for determining these important molecules directly in solution. Recently developed strategies for combining 2D-NMR, Distance Geometry ${ }^{8-10}$ or Molecular Dynamics methods ${ }^{11 \cdot 14}$ have the potential to fill this role. Many different interesting DNA structures, i.e., duplexes with sheared tandem GA mismatch ${ }^{9.15}$, intramolecular ${ }^{16}$, or intermolecular G-tetrads ${ }^{17}$, immobile Holliday Junctions ${ }^{18}$, purine-pyrimidine-pyrimidine ${ }^{19-20}$ or pyrimidine-purinepurine triplexes ${ }^{21}$, parallel stranded $\mathrm{C}^{+} \mathrm{C}$ pairing duplexes ${ }^{22-23}$, homo base-paired parallel stranded duplexes ${ }^{24}$ or even parallel duplexes with intercalated $\mathrm{C}^{+} \mathrm{C}$ base pairing (i-motif) ${ }^{25}$, have been extensively investigated worldwide. These have broadened our understanding of the role these important molecules can adopt.

One of the limitations of these studies by the NMR method has been the difficulty of obtaining DNA sequences with well-resolved NMR peaks for accurate peak volume integration and distance measurements, which is especially true for triplex, tetraplex or humo base-paired parallel duplex studies since these special structures usually dG(i-Bu) : N-isobutyryl deoxyguanosine; $\mathrm{dT}$ : deoxythymidine. 
consist of homo purines or pyrimidines in one strand. This restriction often results in highly overlapped NMR spectra ${ }^{19,21}$, as the cross peaks of the aromatic to $\mathrm{HI} / \mathrm{H} 2^{\prime} / \mathrm{H} 2^{\prime \prime} / \mathrm{H}^{\prime} / \mathrm{H} 4^{\prime} / \mathrm{H} 5^{\prime} / \mathrm{H} 5^{\prime \prime}$ protons of the purines generally grouped in one specific area while those of the pyrimidines group in another area. This causes the volume integrations of the overlapped peaks to be inaccurate, or make spectra assignments impossible. The strong $\mathrm{CH} 5-\mathrm{CH} 6$ cross peaks further complicate this overlapping phenomenon. Three-Dimensional NOESY-TOCSY experiments ${ }^{26}$ were thus used to solve this overlapping problem. Here, we used another approach to this formidable problem, i.e., by specifically deuterating the aromatic protons ( $\mathrm{H} 6$ or $\mathrm{H} 8$ ) of the overlapping region and thus simplifying the otherwise complicated, overlapped spectra. Since the most important information of the nucleic acid structure determined by NMR experiments come from the aromatic to $\mathrm{H} 1^{\prime} / \mathrm{H} 2^{\prime} / \mathrm{H} 2^{\prime \prime} / \mathrm{H} 3^{\prime} / \mathrm{H} 4^{\prime} / \mathrm{H} 5^{\prime} / \mathrm{H} 5^{\prime \prime}$ regions, this approach will be valuable to the NMR community. Thus we here describe a simple one-pot procedure for making all four protected, deuterated deoxyribonucleotides suitable for synthesizing phosphoramidites used in automatic DNA synthesis. These deuterium containing oligodeoxynucleotides can also be used to probe the dynamics of DNA molecules $^{27}$.

Scheme 1 shows the deuterium exchange reaction of 5'-DMT dC(Bz), 5'-DMT dG(iBu), and 5'-DMT $\mathrm{dA}(\mathrm{Bz})$. The exchange reactions were performed in Scheme - 1 dimethylsulfoxide- $\mathrm{d}_{6}\left(\right.$ DMSO- $\left.\mathrm{d}_{6}\right)$ solution using either methanol- $\mathrm{d}_{4}$ or deuterium oxide as deuterium sources with various amounts of bases as catalysts. During the deuteriation reaction, a small amount of the $\mathrm{N}$-protecting group was stripped. The NMR spectra of the crude reaction mixtures showed that $15 \%$ of the benzoyl at the N4 of the cytidine, $30 \%$ of benzoyl at the N6 of adenosine and $20 \%$ of the isobutyryl groups at the $\mathrm{N} 2$ of guanosine were deprotected during the deuterium exchange reactions. The stripped unprotected groups on the deuterated deoxyribonucleotides were re-protected by the addition of a freshly prepared active ester of either benzoyl hydroxybenzotriazole (for $\mathrm{dC}$ and $\mathrm{dA}$ ) or isobutyryl hydroxybenzotriazole (for $\mathrm{dG}$ ) to the deuterated<smiles>Cn1ccc(NC(=O)c2ccccc2)nc1=O</smiles>

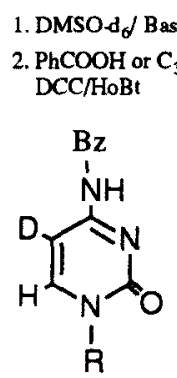

DC DT<smiles>CCn1c(=O)c2nc[nH]c2n(CC(C)C)c1=O</smiles><smiles>[R]OC1(O)OCCC1O</smiles><smiles>[2H]c1nc2c(=O)n(CC(Br)CBr)c(=O)n(CC)c2[nH]1</smiles>

DA 
solution without purification. After final silica gel flash chromatography, this one-pot procedure gave good yields of 5'-hydroxyl- and base protected deuterated deoxyribonucleotides (60-70\%) ready for the well-established phosphoramidite synthesis. The deuterium exchange reaction at 6-H of 5'-DMT-dT turned out to be very slow, and decomposition was observed when the reaction temperature was raised. The deoxyribonucleotide thymidine was thus used as starting material for deuterium exchange reaction, which was carried out by combining the methods of Rabi et al. ${ }^{28}$ and Ti et al. ${ }^{29}$ with some modification as shown in

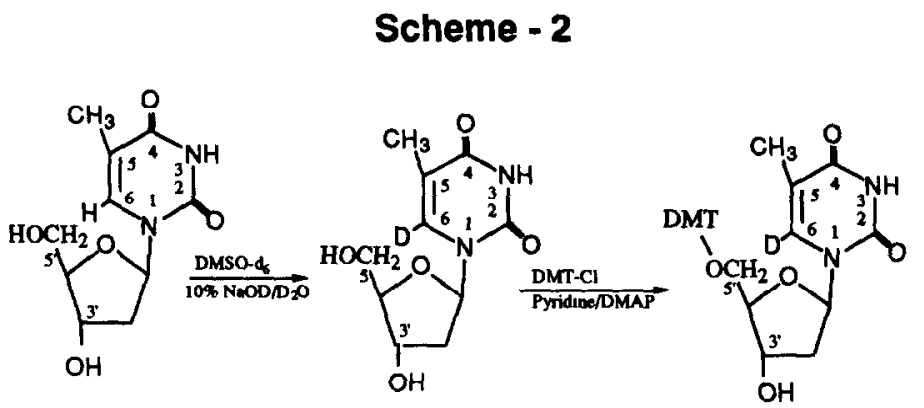

Scheme II.

\section{Experimental section}

The 5'-Dimethoxytritylated Deoxynucleotide Derivatives, deoxythymidine, Dicyclohexylcarbodiimide, and hydroxybenzotrizle were purchased from Peninsula Lab. (USA). DMSO- $\mathrm{d}_{6}$, methanol- $\mathrm{d}_{4}$, and deuterium oxide were purchased from Aldrich Chem CO. (USA). Reagent grade solvents and HPLC grade solvents were brought from local suplier ALPS Chem CO. (TAIWAN).

Preparation of Benzoyl or Isobutyryl hydroxybenzotriazole: To a solution of benzoic acid (1.22 $\mathrm{g}, 10 \mathrm{mmol})$ or isobutyric acid $(0.95 \mathrm{~mL}, 10 \mathrm{mmol})$ and 1 -hydroxybenzotriazole $(1.48 \mathrm{~g}, 11 \mathrm{mmol})$ in $\mathrm{CH}_{2} \mathrm{Cl}_{2}$ ( $(50 \mathrm{~mL})$ was added Dicyclohexylcarbodiimide $(2.06 \mathrm{~g}$., $10 \mathrm{mmol})$. The mixture was stirred for 5-6 hours at room temperature and then filtered to remove the dicyclohexylurea. The resulting mixture was stored in desiccator for funure use.

Synthesis of 6-D 5'-DMT-dC(Bz); A solution of 5'-DMT-dC(Bz) (190 mg, $0.3 \mathrm{mmol})$ dissolved in a mixture of DMSO-d $_{6}(0.75 \mathrm{~mL})$, sodium methoxide $(80 \mathrm{mg})$, and methanol- $\mathrm{d}_{4}(2.8 \mathrm{~mL})$ was flushed with nitrogen for 5 minutes and then heated at $95^{\circ}$ in an oil-bath for 60 hours until the NMR spectrum of the brown solution showed that the C-6 protons has completely exchanged. The resulting mixture was then evaporated to remove methanol, and to the residue was added freshly prepared benzoyl-HOBt in $\mathrm{CH}_{2} \mathrm{Cl}_{2}(1 \mathrm{mmol}$ in $5 \mathrm{~mL}$ ). After 3 hours, a sodium carbonate solution $(5 \%, 20 \mathrm{~mL})$ was added, and the mixture was extracted with ethyl acetate $(3 \times 10 \mathrm{~mL})$. The combined organic solvent was evaporated and the residue eluted through silica gel flash chromatography (prewashed with $\mathrm{CH}_{2} \mathrm{Cl}_{2} / 5 \%$ triethylamine) using $\mathrm{CH}_{2} \mathrm{Cl}_{2}: \mathrm{CH}_{3} \mathrm{OH}$ : triethylamine $(95: 5: 0.5, \mathrm{v} / \mathrm{v})$ as eluent to get the desired 6-D 5'-DMT-dC(Bz) (140 mg, 74\% yield). Figure 1 shows the partial NMR spectrum from 5 to 9 ppm. It is clearly that nearly all $6 \mathrm{H}$ of 5 '-DMT-dC(Bz) signals (denoted by arrow) were disappeared and demonstrated the successful incorporation of deuterium.

Swnthesis of 8-D 5'-DMT-dA(Bz): To a solution of 5'-DMT-dA(Bz) (65 mg, 0.1 mmol) in DMSO-d 6 (2.4 mL) was added a buffer solution $(0.2 \mathrm{M}, \mathrm{pH} 7.1)$ of deuterium oxide $(2 \mathrm{~mL})$, sodium phosphate monobasic $(0.92 \mathrm{mg})$ and sodium phosphate dibasic $(71.8 \mathrm{mg})$. The solution was flushed with nitrogen for 5 minutes and then heated at $90^{\circ}$ in an oil-bath for 36 hours. The resulting mixture was worked out as above to yield 8-D 5'-DMT-dA(Bz) (45 mg, $70 \%$ ). The successful substitution of $8 \mathrm{H}-5^{\prime}-\mathrm{DMT}-\mathrm{dA}(\mathrm{Bz})$ with deuterons was demonstrated in Figure 1-a (denoted 

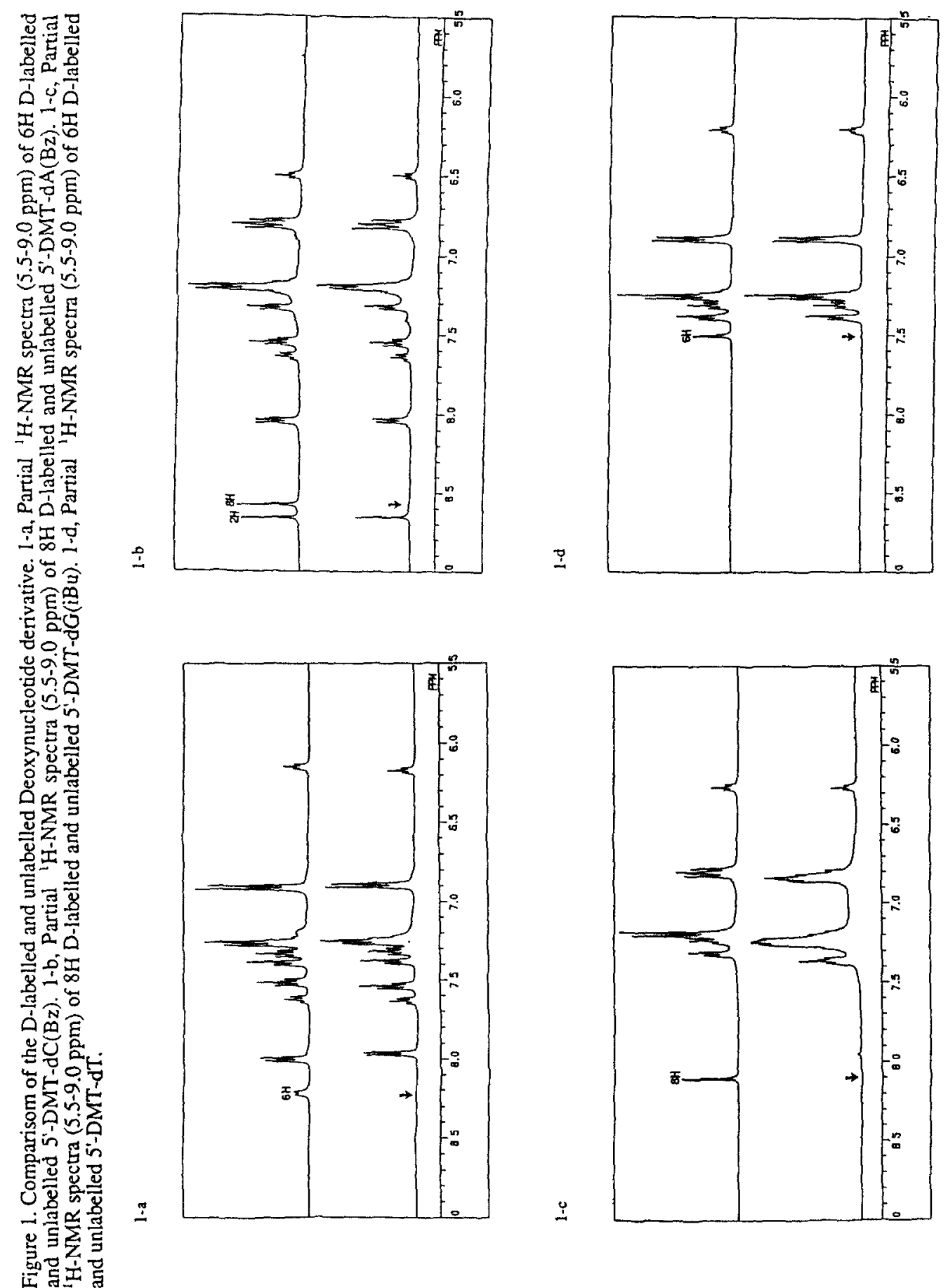

鱼思

งิํㅗㄴ

in

政

的步

$\sum$

定

न

负定

?I

唡家

过合

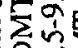

is
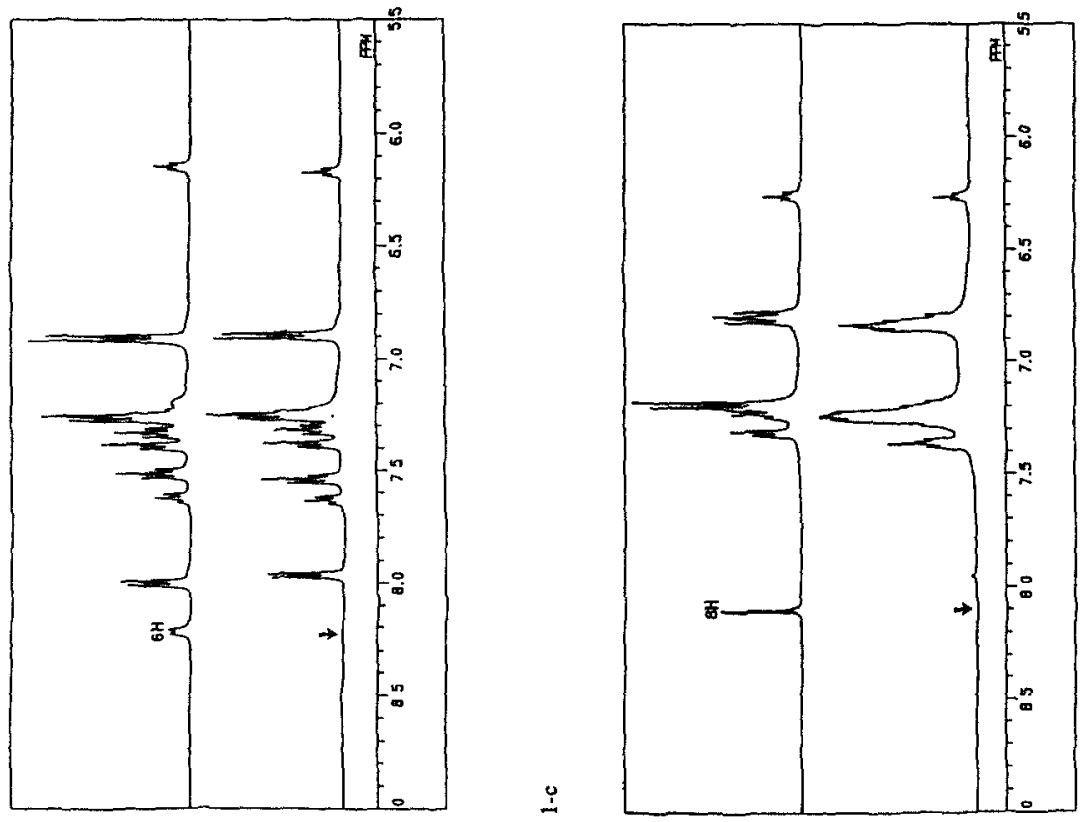

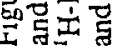


by arrow). The assignment of $8 \mathrm{H}(8.55 \mathrm{ppm})$ and $2 \mathrm{H}(8.60 \mathrm{ppm})$ was carried out utilized the combination of NOESY and molecular modelling (Insight IL/Discover, Biosym Inc.) techniques. The strong NOE cross peak in NOESY spectrum of $8 \mathrm{H}-1$ ' $\mathrm{H}$ agree with the modelling result with the interprotons distance of $\sim 3.2 \AA$. Whereas $2 \mathrm{H}-1$ 'H $(\sim 5.9 \AA)$ showed no observable NOE cross peak (unpublished results).

Synthesis of 8-D 5'-DMT-dG(iBu): To a solution of 5'-DMT-dG(iBu) $(60 \mathrm{mg}, 0.1 \mathrm{mmol})$ in DMSO-d 6 (1.0 mL) was added a buffer solution $(0.2 \mathrm{M}, \mathrm{pH} 7.1)$ of deuterium oxide $(2 \mathrm{~mL})$, sodium phosphate monobasic $(0.92 \mathrm{mg})$ and sodium phosphate dibasic $(71.8 \mathrm{mg})$. The solution was flushed with nitrogen for 5 minutes and then heated at $90^{\circ}$ in an oil-bath for 24 hours. The resulting mixture was worked out as above to yield 8-D 5'-DMT-dG(iBu) $(44$ $\mathrm{mg}, 69 \%$ ). Again, Figure 1-c shows nearly all 8-H were exchanged to deuterium (denoted by arrow).

Synthesis of 6-D 5'-DMT-dT; A solution of dT (242 mg, $1.0 \mathrm{mmol})$ dissolved in a mixture of DMSO-d 6 (3.0 mL) and $10 \% \mathrm{NaOD} / \mathrm{D}_{2} \mathrm{O}(1.0 \mathrm{~mL})$ was flushed with nitrogen for 5 minutes, and was then heated at $135^{\circ}$ in an oil-bath for 48 hours. The resulting mixture was diluted with water $(20 \mathrm{~mL})$ and extracted with ethyl acetate $(3 \times 10 \mathrm{~mL})$. The aqueous solution was lyophilized to remove water, and the residue was dissolved in pyridine $(5 \mathrm{~mL})$. To the solution was added $5 \mathrm{mg}$ of $4,4^{\prime}-\mathrm{N}, \mathrm{N}$-dimethylaminopyridine and $0.67 \mathrm{~g} 4,4^{\prime}$-dimethoxytrityl chloride. The reaction was continued for three hours. Twenty $\mathrm{mL}$ of $5 \%$ sodium carbonate solution was then added, and the mixture extracted with ethyl acetate $(3 \times 10 \mathrm{~mL})$. The combined organic solvent was evaporated, and the residue eluted through a silica gel column as above to get $408 \mathrm{mg}$ (75\% yield) of the desired 6-D 5'- dT. As shown in Figure 1-d. The much reduced $(>95 \%) 6-\mathrm{H}$ signals (denoted by arrow) confirmed the successful substitution of deuterium.

\section{Acknowledgment:}

Support for this research provided by the National Science Council, Taiwan, (NSC 81-0208-N-001-70 \& NSC 82-0208-M-003-014) are gratefully acknowledged.

\section{References:}

1) O. Kennard, W. N. Hunter, Quart Rev. Biophys. 1989, 22, 327.

2) R, E. Dickerson, D.S. Goosdell, M. L. Kopka, P. E. Pjura, J. Biomol Struct. Dyn, 1987, 5, 557.

3) A. D. DiGabriele, M. R. Sanderson, T. A. Steitz, Proc. Natl. Acad. Sci. U.S.A. 1989, 86, 1816.

4) A. H.-J. Wang, G. J. Quigley, F. J. Kolpak, G.V. D. Marel, J. H.V. Boom, A. Rich, Science 1981, 211, 171.

5) M. McCall, T. Brown, W. N. Hunter, O. Kennard, Nature 1986, 322, 661.

6) F. Aboul-ela, G. Varani, G. T. Walker, I. J. Tinoco, Nucleic Acids Res.1988 16, 3559.

7) G. R. Clark, D.G. Brown, M.R. Sanderson, T. Chwalinski, S. Neidle, J. M. Veal, R.L. Jones, W. D.Wilson, G. Zon, E. Garman, D. I. Stuart, Nucleic Acids Res. 1990, 18, 5521.

8) J. W. Cheng,S. H. Chou, M. Salazar, B. Reid, J. Mol. Biol. 1992, 228, 118.

9) S. H. Chou, J. W. Cheng, O. Y. Fedoroff, V. P. Chuprina, B. Reid, J. Amer. Chem. Soc. 1992, 114, 3114.

10) S. H. Chou, J. W. Cheng, B. Reid, J. Mol Biol. 1992, 228, 138.

11) R. Boelens, T. M. G. Koning, R. Kaptein, J. Mol. Struc. 1988, 173, 299.

12) C. B. Post, R. P. Meadows, D. G. Gorenstein, J. Am. Chem. Soc 1990. 112, 6796.

13) K. Kaluarachchi, R. P. Meadows, D. G. Gorenstein, Biochemistry 1991, 30, 8785.

14) U. Schmitz, D. A. Peralman, T. L. James, J. Mol. Biol. 1991, 221, 271.

15) Y. Li, G. Zon, W. D. Wilson, Proc. Natl. Acad. Sci. U.S A.1991, 88, 26.

16) F. W. Smith, J. Feigon, Nature 1992, 356, 164. 
17) Y. Wang, C. D. L. Santos, X. Gao, K. Greene, D. Live, D. J. Patel, J. Mol. Biol. 1991, 222, 819.

18) S. M. Chen, F. Heffron, W. J. Chazin, Biochemistry 1993, 32, 319.

19) R. Macaya, E. Wang, P. Schultze, V. Sklenar, J. Feigon, J. Mol. Biol $1992, .225,755$.

20) I. Radhakrishnan, D. J. Patel, Biochemistry 1992, 31, 2514.

21) I. Radhakrishnan, C. D. L. Santos, D. J. Patel, J. Mol. Biol.1991, 221, 1403.

22) J. Luo, M. H. Sarma, R. D. Yuan, R. H. Sarma, FEBS 1992, 306, 223.

23) D. S. Pilch, R. H. Shafer, J. Am. Chem. Soc. 1993, 115, 2565.

24) H. Robinson,A. H. J. Wang, Proc. Natl. Acad. Sci. USA 1993, 90, 5224.

25) K. Gehring, J. L. Leroy, M. Gueron, Nature 1993, 363, 561.

26) I. Radhakrishnan, D. J. Patel, J.Am.Chem.Soc.1993, 155,1615.

27) W. C. Huang, J. Orban, A. Kintanar, B. Reid, G. P. Drobny, J. Am.Chem. Soc.1990, 112, 9059.

28) J. A. Rabi, J. J. Fox, J. Amer. Chem. Soc. 1973, 95, 1628.

29) G. S. Ti, B. L. Gaffney, R. A. Jones, J. Amer. Chem. Soc.1982, 104, 1316.

(Received in USA 29 November 1993; accepted 25 January 1994) 